\title{
Nome social: uma conquista dos movimentos sociais desconhecida por serviços de atenção básica em um município do Rio Grande do Sul
}

\author{
Analidia Rodolpho Petry, D.Sc.*, William Vinicius Kleinpaul**
}

*Docente do Curso de graduação em Enfermagem da Universidade de Santa Cruz do Sul (UNISC)-RS, Integrante do Grupo de estudos e pesquisa em saúde - GEPS (UNISC), **Enfermeiro formado pela Universidade de Santa Cruz do Sul-RS e integrante do Grupo de estudos e pesquisa em saúde - GEPS (UNISC)

\begin{abstract}
Resumo
Objetivo: Identificar as percepções dos profissionais de saúde, de nível médio e superior de saúde, que atuam nas Estratégias de Saúde da Família e Unidades Básicas de Saúde de uma cidade do interior do Rio Grande do Sul, sobre o Nome Social. Material e métodos: Pesquisa exploratória de cunho qualitativo. A coleta de dados se deu através de uma entrevista semiestruturada, gravada e posteriormente transcrita. A pesquisa foi aprovada pelo Comitê de Ética da Universidade de Santa Cruz do Sul com protocolo n²58.073/13. Resultados: O expressivo número de entrevistados que desconhecem o significado de Nome Social se deve a pouca divulgaçáo do Decreto no 49.122, de 17 de maio de 2012. Conclusão: Transexuais e travestis são tratados conforme as concepções sociais e morais dos profissionais que os atendem, podendo implicar em um cuidado de saúde pouco humanizado.
\end{abstract}

Palavras-chave: atenção primária de saúde, profissional de saúde, identidade de gênero, pessoas transgênero.

\section{Abstract \\ Social name: social movements conquest unknown by primary care health services in a city of Rio Grande do Sul}

Objective: This study aimed to identify the professional's perception about Social Name. The study was carried out in a town of Rio Grande do Sul, with primary health care professionals. Methods: This is an exploratory research with qualitative approach. The data collection was carried out through a semi-structured interview, recorded and transcribed. The study was approved by the Ethics Committee of the University of Santa Cruz do Sul under Protocol n²58 073/2013. Results: Interviewed are not informed about the meaning of Social Name, due to weak dissemination of Decree $\mathrm{n}^{\circ} 49.122$, May 17, 2012 among them. Conclusion: Transsexuals and transvestites are treated according to professional's social and moral perceptions what entails in a poor health care.

Key-words: primary health care, health professional, gender identity, transgendered person. 


\section{Resumen}

\section{Nombre social: una conquista de los movimientos sociales desconocida de los servicios de atención primaria en una ciudad de Rio Grande do Sul}

Objetivo: Identificar las percepciones de los profesionales, de nivel medio y superior de la salud, que trabajan en la Atención Primaria de Salud, de una ciudad en el interior de Rio Grande do Sul, acerca del Nombre Social. Material y métodos: Investigación exploratoria con enfoque cualitativo. Se recogieron datos a través de una entrevista semiestructurada, grabada y transcrita. El estudio fue aprobado por el Comité de Ética de la Universidad de Santa Cruz do Sul bajo el protocolo N²58073. Resultados: Los entrevistados desconocen el significado de Nombre Social debido a la escasa difusión del Decreto n49.122 del 17 de mayo de 2012. Conclusión: Transexuales y travestis son tratados de acuerdo con las concepciones sociales y morales de los profesionales de salud, lo que puede resultar en un cuidado de salud poco humanizado.

Palabras-clave: atención primaria de salud, personal de salud, identidad de género, personas transgénero.

\section{Introdução}

Na sociedade contemporânea, cada vez mais se tem observado que pessoas que apresentam incongruência entre o gênero com o qual se identificam e seu corpo biológico têm procurado tanto tratamentos hormonais quanto cirúrgicos para adequarem seu corpo à sua expressão de gênero. Tal condição é denominada, pelo Manual Diagnóstico e Estatístico de Transtorno Mentais (DSM - V) como Disforia de Gênero [1].

Importa salientar que gênero é o comportamento de cada indivíduo frente à sociedade conforme sua interpretação cultural do sexo, enquanto que sexo se refere ao padrão biológico binário feminino ou masculino. Entretanto, a adequação da imagem corporal ao gênero de identificação não é suficiente para que o indivíduo seja reconhecido como tal. A incongruência entre a imagem corporal representada pelo gênero de identificação e o nome que o indivíduo apresenta nos seus documentos também causa sérios constrangimentos e embaraços aos transexuais e travestis. No Rio Grande do Sul, a Carteira do Nome Social, destinada à população transgênera foi criada pelo Decreto no 49.122, de 17 de maio de 2012 [2]. Trata-se de um documento que tem por princípio fazer com que os indivíduos recebam tratamento nominal nos órgãos e entidades do Poder Executivo Estadual, conforme o princípio da Dignidade da Pessoa Humana, previsto no artigo $5^{\circ}$ da Constituição Federal.

Os locais que, atualmente, têm aderido ao uso do Nome Social são escolas e centros de saúde, buscando desta forma aproximar estas pessoas dos serviços ofertados na área da saúde e educação garantindo assim seu acesso e permanência nestes ambientes. O uso do Nome Social tem por objetivo fazer com que transexuais e travestis possam sentir-se inseridos e legitimados no contexto da nossa sociedade heteronormativa.

O nome representa, desde o nascimento, uma característica de identificação e de inclusão social que dará significado ao indivíduo, frente à sociedade, tornando-o assim, integrante constituinte dela. Trata-se de uma marca que o define tanto em consonância ao tempo em que ele nasceu quanto em relaçáo ao sexo a que ele pertence. Os nomes seguem padróes culturais que são localizados no tempo e no espaço social no qual o indivíduo está inserido [3]. Ao identificar um filho através de um nome, os pais almejam inseri-lo no contexto social demarcando suas crenças, suas concepçóes morais, religiosas e sociais.

Há regiôes que trazem esta marca identificada na homenagem que se faz aos santos ou a personalidades históricas, por exemplo. Complementarmente, o sexo biológico também determina o nome da pessoa e a posiciona a comportamentos e a normatizaçóes específicas e socialmente determinadas e reguladas para corpos constituídos por falos ou não [4].

Importa considerar que a sociedade "através da sua história, constrói uma figura rígida de homem ou mulher e forçam os indivíduos que dela participam a uma conduta estrita às normas estabelecidas" para cada sexo, se constituindo em uma "marca distintiva na sociedade, determinante de uma forma de individualização, mesmo após a morte" [3:255]. Entretanto, há pessoas que escapam a estas normas e, com e através de seus corpos, desestabilizam o siste- 
ma heteronormativo vigente, posicionando-os como sujeitos travestis ou transexuais. Em decorrência de várias lutas impetradas pelos movimentos sociais, estas populaçóes conquistaram o direito a utilizar o Nome Social no sistema educacional e também no sistema de saúde, em alguns estados brasileiros [5-6].

Esta pesquisa tem como objetivo identificar as percepçóes dos profissionais, de nível médio e superior de saúde, que atuam nas Estratégias de Saúde da Família e Unidades Básicas de Saúde de uma cidade localizada no interior do Rio Grande do Sul, quanto ao Nome Social.

\section{Material e métodos}

Trata-se de uma pesquisa qualitativa exploratória, pois visa evidenciar a realidade vivida pelos sujeitos pesquisados sem quantificar os eventos, mas procurando entender seu universo de crenças e valores. Desse modo, nossa pesquisa buscou problematizar a realidade vivenciada pelos profissionais de saúde no atendimento à população transgênera, população esta, que fogem e desestabilizam o sistema social heteronormativo. Complementarmente, a pesquisa exploratória estuda mais profundamente um assunto pouco conhecido e explorado [7]. Desta forma nosso estudo deteve-se em explorar as experiências vivenciadas pelos profissionais de saúde sobre os atendimentos prestados às pessoas que pertencem ao universo transgênero.

As entrevistas foram realizadas entre julho de 2012 e junho de 2013 e tiveram aproximadamente uma hora de duração. Foram sujeitos deste estudo vinte e seis profissionais de saúde de nível técnico e superior, formados há pelo menos um ano, e que trabalham nas Unidades Básicas de Saúde e nas unidades de Estratégias de Saúde da Família do município de Santa Cruz do Sul/RS. Este critério de inclusão foi estipulado considerando que profissionais que atuam na Saúde Coletiva devam estar informados de discussóes gerais de políticas públicas. A faixa etária variou entre 24 e 56 anos e o tempo de atuação na área oscilou entre três meses a quinze anos. As entrevistas foram realizadas no local de trabalho dos entrevistados, em momentos de menor demanda de atendimento, fato que resultou em um entrave na coleta dos dados, demandando em longos tempos de espera por parte do entrevistador.

Os entrevistados assinaram o Termo de Consentimento Livre e Esclarecido, conforme a resolu- ção 466/2012. A pesquisa foi aprovada pelo Comitê de Ética e Pesquisa da Universidade de Santa Cruz do Sul sob protocolo no 258.073. Optou-se pelo uso de codinomes para manter o anonimato dos respondentes. Desse modo, os entrevistados são identificados pela sua categoria profissional seguida da ordem em que foram entrevistados. Assim, temos: Enfermeiro-3; Odontólogo-1; Médico-2; Téc. Enferm-9.

Após as entrevistas, as falas foram transcritas de modo integral para posterior análise do seu conteúdo obedecendo às etapas de pré-análise, exploração do material e tratamento dos resultados. A análise de conteúdo diz respeito a uma técnica de pesquisa que permite replicar e validar inferências sobre os dados de um contexto específico [8]. O material coletado foi lido e manuseado de forma exaustiva, o que permitiu captar as ideias centrais e as estruturas relevantes, desvelando, em duas unidades analíticas, a percepçáo dos profissionais sobre o uso do Nome Social nos serviços de saúde que atendem.

\section{Resultados e discussão}

\section{Bloco 1- O Nome Social nos Serviços de Atençáo Básica: um desafio a ser transposto}

Os movimentos sociais ao longo da história atingiram inúmeras conquistas em relação aos direitos e inclusão social para a população transgênera. Uma destas conquistas foi do Nome Social nos registros escolares e nos serviços de saúde, práticas que objetivam minimizar os efeitos do preconceito e da discriminação que atingem esta população específica [2]. Assim, os movimentos sociais são responsáveis por impulsionar as açóes públicas que garantem o respeito à identidade de gênero nos espaços públicos e tem sido legitimado e ratificado por entidades como o Conselho Regional de Medicina do Estado de São Paulo (CREMESP) e o Ministério da Educação e Cultura (MEC). Em nossa pesquisa observamos que alguns profissionais de saúde entraram em contato com a temática do Nome Social, porém não possuíam conhecimento aprofundado para defender ou utilizar a informaçáo com segurança no cotidiano do seu trabalho:

\footnotetext{
“... acho que eu não ouvi falar teoricamente..." (Odontólogo 1)
} 
"Nome Social?...Este termo específico eu não conheço." (Profissional de nível superior II-III)

“... só uma coisa pela televisão mesmo, naqueles programas sensacionalistas....” (Técnica de enfermagem 8).

O relato acima indica que a informação sobre o Nome Social se deu através da mídia sensacionalista e, através das informaçóes advindas destes meios, o profissional, independente do seu grau de formação, atribui significado ao tema. A televisão é a segunda maior mídia utilizada no Brasil [9] e as informaçóes passadas por ela atingem várias pessoas e de várias culturas, sendo este o motivo para que haja várias interpretaçôes sobre uma mesma temática. A mídia contribui para a formaçáo de opiniāo e posterior tomada de atitude dos indivíduos e, no caso dos profissionais de saúde, isto não é diferente [10].

Outros profissionais entrevistados referiram ter tido conhecimento sobre o Nome Social através de outros tipos de mídia:

"Até tinha cartaz aqui que nós olhamos que eles podem trocar...eles têm direito de trocar de nome, né?....mas não sei se esta questão é mais de cartório... mas não estou bem dentro deste assunto" (Enfermeira 5).

O excerto acima faz referência a um cartaz produzido pela Secretaria Estadual de Saúde para vinculação nos serviços. Trata-se de uma publicaçáo que está disponível nos serviços e que, em nossa pesquisa, foi referida apenas por um entrevistado. Importa salientar que a insegurança quanto ao local para aquisição da Carteira de Nome Social indica desconhecimento sobre os mecanismos de uso deste direito, de modo amplo. Nossa pesquisa evidencia a fragilidade de informaçáo que os profissionais de saúde da atenção básica possuem tanto sobre o percurso que o candidato à utilização do Nome Social deve realizar, quanto à falta de apropriação desta política pública enquanto um conhecimento que pode facilitar a vida dos usuários:

“... eu não sei se é só em Porto Alegre ou no estado do Rio Grande do Sul que pode? Não é no Brasil todo? É uma lei federal? Eu pensei que era estadual.” (Médico 3)
Podemos depreender, pelo relato em destaque, que o entrevistado não se apropriou das informações quanto ao Nome Social, não sabendo o local de aquisição e de abrangência do benefício. Estas informaçóes estão contidas no art. 5 do decreto $49122 / 2012$, no qual menciona que deve ser confeccionado no Instituto Geral de Perícia, órgão responsável pela regulamentaçáo do processo de confecção da referida carteira. Dentre os entrevistados, percebemos haver o entendimento de que o Nome Social seria equivalente a um pseudônimo que estariam utilizando de modo informal na comunidade:

'Nome Social, que eu sei que eles dizem mui-
to aqui na vila, é o nome de guerra deles, né?
Por exemplo, assim... Paulo fica Paulete, estas
coisas assim..." (Técnica de enfermagem 10)

O Nome Social é um direito que os indivíduos transgêneros têm de utilizar o nome que se adeque a sua expressão de gênero. $\mathrm{O}$ "nome de guerra" ao qual a entrevistada se refere é o nome que os transexuais e travestis elegiam para serem nominados e que náo possuíam respaldo legal. Entendemos que o despreparo e o desconhecimento sobre este direito do usuário transgênero pode prejudicar o seu atendimento em termos de reconhecimento da sua dignidade enquanto pessoa, pois o nome denomina normas e valores relativos ao gênero e a sexualidade, assim como a forma de se relacionar com o mundo [11]. A não identificação do usuário pelo seu nome social pode acarretar em sérios inconvenientes e constrangimentos, tanto sociais quanto de cunho pessoal. O depoimento abaixo elucida uma situação de constrangimento vivenciada em uma unidade de Estratégia de Saúde da Família:

“... até estes dias foi engraçado! A médica foi chamar um paciente que estava na sala de espera e chamou pelo nome que estava na ficha. Daí, quando ela olhou, assim, eu acho que ela nunca tinha visto, não sabia .. ela olhou assim, acho que ela ficou meio estranha ...daí ela chamou de novo, pensando que estava vindo a pessoa errada! Daí ele disse: é, sou eu mesmo!" (Enfermeira1)

Situaçôes de constrangimento conforme a referida acima podem ser evitadas através da implementação do Nome Social nos serviços de saúde. Conforme o Ministério da Saúde [12], a gestão e 
implementação do Sistema Único de Saúde também é obrigação dos municípios, que devem trabalhar de forma integrada com as demais esferas do governo, através de políticas intersetoriais, garantindo saúde com qualidade. Em outras palavras, os municípios têm como dever apropriar-se das políticas existentes e transmitir informaçóes coerentes e efetivas aos profissionais de saúde que fazem do atendimento diário a sua prática profissional.

Este bloco temático nos leva a considerar a importância de maior divulgação do Decreto 49.122/2012 no Estado, pois a sua utilizaçáo evitaria constrangimentos tanto para a população transgênera quanto para o profissional de saúde. Os documentos de registro público, quando utilizados de forma que não mais expressam qualidades existentes, se apresentam como uma forma de estigma à pessoa transexual [11].

\section{Bloco II - Corpo, gênero, sexo e sexualidade: percepçóes dos profissionais de saúde}

Além das situações de não conhecimento dos direitos da população transgênera, há que considerar a importância da percepção cultural dos profissionais de saúde sobre corpo, gênero sexo e sexualidade e o quanto esta percepçáo implica no atendimento que prestam. Indivíduos transgêneros colocam em xeque o sistema heteronormativo e podem desestabilizar os profissionais de saúde em relaçáo ao modo como compreendem o mundo e a sociedade.

“...o que é difícil é quando ele quer que tu chame ele de ... e ele náo atende pelo nome que está ali no prontuário porque ele acha que ele tem outro nome. Só que o outro nome não é o que consta nos documentos ... então, é bem difícil!" (Enfermeira 4)

Situaçóes como a relatada acima indicam a compreensão social heteronormativa que a profissional apresenta. A referência ao paciente é efetuada no masculino, apesar do sujeito que está diante da profissional de saúde se vestir, se comportar e apresentar uma expressão de gênero feminina. Constata-se, portanto, que a aplicação do Decreto 49.122/2012 dependerá, não apenas da sua obrigatoriedade, mas de discussóes que devem ser feitas com e entre os profissionais de saúde para que repensem suas próprias concepçóes de corpo, sexo e gênero. Outro aspecto a considerar decorre de que as normas que regulamentam o uso deste dispositivo são regidas de forma individual por cada Estado, o que dificulta sua veiculação nacional. Nas instituiçóes de ensino, 14 estados aderiram ao uso do Nome Social [5]. As Secretarias de Educaçáo perceberam a importância da utilizaçáo do Nome Social, pois o uso do nome civil provoca constrangimento na população transgênera, sendo uma das causas da evasão escolar [11]. Nesta direção, podemos problematizar o quanto o uso do nome civil pode afastar a populaçáo transgênera dos serviços de saúde.

Outro dado encontrado foi a não identificação adequada da condição de gênero do usuário que possui potencial para utilizaçáo do nome social.

“... este que se veste de mulher ele mulher é meio transexual. Ele usa na documentação o nome de homem... é que aqui não está escrito tu chama e daí entra a pessoa... daí, no primeiro momento, dá um impactozinho..." (Médico 3 ).

O profissional faz referência à condição de "meio transexual" que o indivíduo apresentaria. Perguntamos o que seria ser "meio transexual"? Compreendemos que a fala indica uma representação cultural atravessada por compreensôes de corpo, sexo, gênero e sexualidade onde ser "meio transexual" poderia ser menos grave do que ser transexual. Este questionamento importa, uma vez que a identidade de gênero do sujeito está sendo negada pelo profissional de saúde e, possivelmente, implica no "impactozinho" que ele sofre ao se deparar com um indivíduo que desestabiliza suas crenças e seus valores morais.

A influência dos valores morais dos profissionais de saúde no atendimento que prestam é evidenciada em alguns estudos [13]. Em relação à população transgênera, entendemos que as compreensóes dos profissionais de saúde sobre corpo, gênero, sexo e sexualidade também são atravessadas pelas concepçóes morais e sociais que apresentam. Alguns entrevistados deixam explicito que não aceitam o modo diferente como algumas pessoas expressam seu gênero e apresentam seus corpos:

\footnotetext{
“... que não se aceita... pra mim já complica um pouco mais quando a pessoa náo se aceita e quer ser uma coisa que não nasceu assim..." (Técnica de enfermagem 1)
} 
O não conformismo da profissional quanto às pessoas que apresentam comportamentos diferentes daqueles heteronormativamente esperados provoca a inquietação da entrevistada. Uma das explicaçóes dadas sobre a depreciação da homossexualidade masculina está relacionada à compreensão de desvio de conduta, criada por uma sociedade machista, onde o homem teria sua honra ferida ao se comportar com características femininas [13]. Estas concepçóes fazem parte do imaginário social e se concretizam no pensamento e nas atitudes dos sujeitos quando se deparam com indivíduos cuja expressão de gênero não segue as normas heterossexuais socialmente legitimadas.

Os valores culturais e sociais têm influenciado o modo como o profissional de saúde, para realizar o atendimento, desconsidera a situação de gênero e sexo da pessoa transgênera:

“... apesar de que a gente fica chocado... assim... a gente não tem tantas habilidades para trabalhar com estes indivíduos, né? Falta assim um manejo mais adequado...a gente faz de conta que aquilo é o mais natural" (Enfermeira 6).

Ao referir "fazer de conta" que a identidade de gênero daquele que é atendido "é o mais natural", a profissional indica que, na a sua compreensão, a identidade de gênero que náo segue a regra heteronormativa é anormal. Esta compreensão vai ao encontro dos estudos que referem a associação entre a baixa procura das lésbicas pelo serviço de saúde e a discriminação e despreparo dos profissionais em atender situaçóes que os desestabilizam em relação às suas crenças e valores morais [14].

Dentre os motivos estão à discriminação, a falta de qualificação dos profissionais, levando os mesmos uma agressão aos direitos humanos básicos, promovendo a vulnerabilidade social da população transgênera. Importa considerar que as políticas públicas apontam que a orientação sexual é um determinante de saúde [15].

Neste bloco temático evidenciamos a deficiência de manejo dos profissionais de saúde no atendimento à populaçáo transgênera. Entendemos que a temática necessita ser problematizada nos currículos acadêmicos, que poderia contemplar conteúdos sobre gênero e orientação sexual com o objetivo de que o aluno não caia em naturalizaçóes e preconceitos [15].

\section{Conclusão}

O direito ao uso Nome Social em espaços públicos no estado do Rio Grande do Sul é um direito adquirido pela população transgênera com o objetivo de, ao serem nominados conforme sua identidade e expressão de gênero possam ser respeitados e legitimados socialmente. $\mathrm{O}$ uso do nome social tem por objetivo garantir-lhes dignidade nos tratos sociais, evitando constrangimentos e humilhações públicas. Esta pesquisa oportunizou visibilizar as percepçóes dos profissionais de saúde, de nível médio e superior, que atuam nas Estratégias de Saúde da Família e Unidades Básicas de Saúde de uma cidade localizada no interior do Rio Grande do Sul, sobre o Nome Social.

A análise dos dados nos levou a entender que o Decreto no 49.122, de 17 de maio de 2012 foi pouco divulgado junto aos serviços de saúde. De modo especial, evidenciamos não ter havido, por parte da Secretaria Estadual de Saúde, açóes que pudessem problematizar questóes relacionadas a corpo, sexo, gênero e sexualidade e instrumentalizar os profissionais a repensarem suas práticas de atendimento à população transgênera.

Outro aspecto apontado por este estudo diz respeito ao modo como as compreensóes sociais e morais dos profissionais de saúde interferem no atendimento que prestam as pessoas que, através de seus corpos e comportamentos desestabilizam o sistema social heteronormativo vigente. Os profissionais que trabalham nos serviços de atenção básica são os agentes que proporcionarão, ou não, a inclusão das pessoas - independente de credo, raça ou identidade de gênero - no sistema de saúde. Desse modo, entendemos que a ética que rege as profissóes de saúde deve perpassar o cuidado prestado à populaçáo, de modo amplo. Para que tal possa ocorrer é necessário repensar os currículos acadêmicos no sentido de incluírem, com urgência, questôes relacionadas a esta temática para que as concepçóes essencialistas dos estudantes possam ser problematizadas ao longo de sua formação.

A pesquisa que subsidiou este artigo problematizou aspectos relacionados ao Nome Social, que é aquele pelo qual a população transgênera prefere ser denominada no seu cotidiano por refletir sua expressáo de gênero. Entendemos que o uso e o entendimento do Nome Social pelos profissionais, nos serviços de saúde, se constituem em um desafio que pode ser transposto através de ações que visem 
a sua divulgação e problematização nos serviços de saúde, de modo amplo.

\section{Referências}

1. Manual Diagnóstico e Estatístico de Doença Mental - DSM-V. Porto Alegre: Artes Médicas; 2014. 998p.

2. Besso SM, Campos JAPST, Paes TS. Transexualismo no Brasil: mudança no corpo e no papel? Rev Direito e Práxis 2010;1(01):165-76.

3. Prochno CCS, Rocha RMG. O jogo do nome nas subjetividades travestis. Psicologia \& Sociedade 2011;23(2):254-61.

4. Santos LH. Heteronormatividade \& Educação. Brasília: Secretaria Especial de Políticas para Mulheres; 2007.

5. Ferreira L. Travestis de 14 estados já podem escolher nome que usaram na escola. 2010. [citado 2015 out 15]. Disponível em URL: http://noticias.r7.com/ educacao/noticias/travestis-de-14-estados-ja-podem-escolher-nome-que-usarao-na-escola-20111028.html.

6. Albuquerque GA, Garcia CL, Alves MJH, Queiroz CMHT, Adami F. Homossexualidade e o direito à saúde: um desafio para as políticas públicas de saúde no Brasil. Rev Saúde em Debate 2013;37(98):516-24.

7. Gil AC. Métodos e técnicas de pesquisa social. São Paulo: Atlas; 2008. 200p.

8. Minayo MCS. O desafio do conhecimento pesquisa qualitativa em saúde. São Paulo: Hucitec; 2007. 406p.
9. Pavlovitsch A. A influência da mídia televisiva na maturaçáo do adolescente. 2008. [citado 2014 dez 20]. Disponível em URL: http://www.redepsi.com. br/2008/03/14/a-influ-ncia-da-m-dia-televisiva-na-matura-o-do-adolescente

10. Cardoso IXF. A influência da televisão sobre as crianças: uma polêmica. [Monografia]. Fortaleza: Faculdade 7 de Setembro; 2008.

11. Cirilo EGA, Miranda MMM. O reconhecimento das identidades de gênero e a internação hospitalar de travestis e transexuais no sistema único de saúde. Revista da Defensoria Pública 2012;5(1):218-31.

12. Brasil. Ministério da Saúde. O SUS no seu município Garantindo saúde para todos. Brasília: Ministério da Saúde; 2009.

13. Conceição MM, Barbosa RJB, Barbosa JS, Borges CER et al. Percepçáo da enfermagem no cuidar às mulheres em processo de abortamento em hospital de referência no interior da Bahia. Enfermagem Brasil 2014;13(1):11-17.

14. Pires LB, Santos DJ, Franco A. A homossexualidade nas revistas científicas da saúde. Seminário Internacional Enlaçando Sexualidades. Bahia; 2011.

15. Lionço $T$. Que direito à saúde para a população GLBT? Considerando direitos humanos, sexuais e reprodutivos em busca da integralidade e da equidade. Saúde e Sociedade 2008;17(2):11-21. 